\title{
Treatment of hepatic metastases with computed tomography-guided interstitial brachytherapy
}

\author{
DARIUSZ KIESZKO ${ }^{1}$, PAWEŁ CISEK ${ }^{1,2}$, \\ IZABELA KORDZIŃSKA-CISEK ${ }^{2}$ and LUDMIŁA GRZYBOWSKA-SZATKOWSKA ${ }^{2}$ \\ ${ }^{1}$ Department of Brachytherapy, St. John's Cancer Center, 20-090 Lublin; \\ ${ }^{2}$ Department of Oncology, Medical University of Lublin, 20-059 Lublin, Poland
}

Received December 21, 2017; Accepted February 22, 2018

DOI: $10.3892 / \mathrm{ol} .2018 .8415$

\begin{abstract}
The aim of the present study was to evaluate the efficacy, safety and tolerability of local treatment of liver metastases of various types of cancer using brachytherapy with computed tomography (CT) imaging. Retrospective analysis of 61 patients with unresectable hepatic metastases treated with CT-guided interstitial high dose rate (HDR) brachytherapy of the liver between April 2014 and December 2016 was performed. Patients were treated with a single fractional dose of 15-25 Gy. Statistical analysis was performed on local relapse free survival (LRFS), progression free survival (PFS) and overall survival (OS) rates across the group. In the 6 and 12-month follow-up periods, the 6- and 12-month LRFS rates were 88.7 and $70.7 \%$, PFS rates were 78.1 and $53.8 \%$ and the OS rates were 96.7 and $79.6 \%$, respectively. In the Cox regression analysis, the $100 \%$ isodose was a statistically significant predictor of LRFS $(\mathrm{P}=0.01)$ and PFS $(\mathrm{P}=0.02)$, but it was not significant in OS $(\mathrm{P}=0.07)$. The $90 \%$ isodose was a statistically significant predictor of LRFS $(\mathrm{P}=0,03)$ but not significant in PFS $(\mathrm{P}=0.17)$ or $\mathrm{OS}(\mathrm{P}=0.25)$. In all patients, no serious complications were observed. Overall, $30 \%$ of patients experienced pain at the injection site, and 50\% exhibited nausea or vomiting. In 2 patients, minor subcapsular bleeding occurred without clinical significance, and 1 patient was diagnosed with a pneumothorax that was not clinically significant. Brachytherapy HDR with CT imaging is an effective and safe method of local treatment of liver metastases. The effectiveness of the treatment is probably dose-dependent, and increases with increasing dosage.
\end{abstract}

Correspondence to: Dr Paweł Cisek, Department of Brachytherapy, St John's Cancer Center, 7 Jaczewskiego, 20-090 Lublin, Poland E-mail:pcisek@interia.eu

Key words: brachytherapy, liver metastases, computed tomography-guided intervention

\section{Introduction}

The liver is one of the most common sites for tumor metastases in different types of cancer, including colorectal cancer, lung carcinoma, ovarian cancer, melanoma, breast carcinoma and esophageal and urogenital tumors $(1,2)$. This organ is a site of metastasis in 25\% of metastatic cancers (3). In Western countries, metastases are the most common type of malignant neoplasms in the liver (3). The analysis of the postoperative course in patients following resection of colorectal cancer reveals that liver metastases occur in $40-60 \%$ of patients (2). The local treatment of secondary liver cancer is based on surgical interventions. Surgery is the main curative treatment for both primary and secondary liver cancer, however, it is feasible in only 20-30\% of cases (4). Local non-surgical methods of liver cancer treatment include radiofrequency ablation, transarterial radioembolization and chemoembolization, cryotherapy (cryoablation), electric pulses (electroporation), laser therapy and various radiotherapy methods $(5,6)$. Radiation therapy is primarily administered as stereotactic teleradiotherapy and three-dimensional conformational radiotherapy (7). In previous years, image-guided brachytherapy has become increasingly popular $(8,9)$. This is due to the possibility of administering high radiotherapy doses to the tumor region, while maintaining a low dose in the remaining healthy liver tissue. This allows for an escalation of the radiation dose above the mean tolerance dose for the whole liver, whilst maintaining local control of the irradiated metastases.

The present study describes the initial results of treatment with the use of liver brachytherapy in the St John's Cancer Center of Lublin (Lublin, Poland), and involved a preliminary retrospective analysis. The aim of the present study was to evaluate the local recurrence-free survival (LRFS), disease-free survival (DFS) and overall survival (OS) rates of the patients. Safety, tolerability, adverse events and the technical feasibility of performing an interstitial liver brachytherapy were evaluated.

\section{Materials and methods}

Group characteristics. The study included all 61 patients with liver metastases undergoing brachytherapy at the St. John's Cancer Center of Lublin between April 2014 and 
December 2016. The patient population comprised 34 males and 27 females, and the median age was 68 $\pm 8,14$ years (range, 36-84). All patients had previously undergone at least one palliative course of chemotherapy; in patients with colon cancer, two lines of chemotherapy were administered. In digestive tract cancer; $2-4$ cycles of LF [fluorouracil, 400 and $600 \mathrm{mg} / \mathrm{m}^{2}$ intravenous (IV), d (day). 1 and 2; calcium folinate, $200 \mathrm{mg} / \mathrm{m}^{2} \mathrm{IV}$, d. 1 and 2]; 4-12 cycles of FOLFIRI (fluorouracil, 400 and $600 \mathrm{mg} / \mathrm{m}^{2} \mathrm{IV}$, d. 1 and 2; calcium folinate, $200 \mathrm{mg} / \mathrm{m}^{2} \mathrm{IV}$, d. 1 and 2; irinotecan, $180 \mathrm{mg} / \mathrm{m}^{2} \mathrm{IV}$, d. 1) or 4-12 cycles of FOLFOX (fluorouracil, 400 and $600 \mathrm{mg} / \mathrm{m}^{2}$ IV, d. 1 and 2; calcium folinate, $200 \mathrm{mg} / \mathrm{m}^{2} \mathrm{IV}$, d. 1 and 2; oxaliplatin, $85 \mathrm{mg} / \mathrm{m}^{2} \mathrm{IV}, \mathrm{d}$. 1) were administered. In breast cancer: 4-6 cycles of AT (doxorubicin, $50 \mathrm{mg} / \mathrm{m}^{2} \mathrm{IV}$, d. 1; docetaxel, $75 \mathrm{mg} / \mathrm{m}^{2} \mathrm{IV}, \mathrm{d}$. 1$)$ or capecitabine $\left(2,500 \mathrm{mg} / \mathrm{m}^{2}\right.$ per os, d. 1-14) were administered. In lung cancer 4 cycles of PN (cisplatin $75 \mathrm{mg} / \mathrm{m}^{2} \mathrm{IV}$, d. 1 and vinorelbine $30 \mathrm{mg} / \mathrm{m}^{2} \mathrm{IV}$, d. 1 and 8.) were administered. In endometrial cancer 6 cycles of TK (paclitaxel $175 \mathrm{mg} / \mathrm{m}^{2}$ IV, d. 1 and carboplatin AUC (Area Under the Curve) 6 IV, d. 1) were administered. In laryngeal cancer 4 cycles of PF (cisplatin $100 \mathrm{mg} / \mathrm{m}^{2} \mathrm{IV}$, d. 1 and fluorouracil $1,000 \mathrm{mg} / \mathrm{m}^{2} \mathrm{IV}, \mathrm{d}$. 1-4.) were administered. In melanoma 6 cycles of dacarbazine $\left(200 \mathrm{mg} / \mathrm{m}^{2} \mathrm{IV}, \mathrm{d}\right.$. 1-5.) were administered. All patients exhibited tumor progression to the liver according to the Response Evaluation Criteria in Solid Tumors (RECIST) scale ver. 1.1 following chemotherapy (10). All liver tumors were inoperable. In 24 patients (39\%), chemotherapy following brachytherapy was used [2-12 cycles of FOLFOX, 4-6 cycles of FOLFLIRI, 6 cycles of cetuximab $\left(400 \mathrm{mg} / \mathrm{m}^{2} \mathrm{IV}\right.$, d. 1 in the first cycle and $250 \mathrm{mg} / \mathrm{m}^{2} \mathrm{IV}$, d. 1 in subsequent cycles)]. None of the patients had received radiotherapy for metastases in the liver. No other methods were used to treat local liver metastases. Group characteristics are summarized in Table I. The present study was approved by the Ethics Committee of the Lublin Medical Chamber (Lublin, Poland) (approval no., LIL-KB-20/2014). Written informed consent was obtained from all participants.

Inclusion criteria. The following inclusion criteria were used to identify patients qualifying for the brachytherapy treatment: Metastatic lesions with a diameter $<8 \mathrm{~cm}$; total lesion diameter, $<12 \mathrm{~cm}$; number of metastatic lesions, $<4$; a lack of direct proximity of large vessels to the lesions; age, 18-85 years; histologically diagnosed cancer from primary lesions or metastatic lesions; lack of possibility of surgical treatment; lack of efficacy of chemotherapy (first and second line chemotherapy); failure and/or intolerance of chemotherapy; lack of patient consent for chemotherapy; the performance status of the patient based on World Health Organization scale (11), $<2$ or Karnofski performance status (11) $>60 \%$; serum creatinine level, $\leq 2 \mathrm{mg} / \mathrm{dl}$; hemoglobin level, $>8 \mathrm{~g} / \mathrm{dl}$-grams per decilitere; white blood cell count, $>2,000 / \mathrm{mm}^{3}$; neutrophil count, $>1,500 / \mathrm{mm}^{3}$; platelets, $>50,000 / \mathrm{mm}^{3}$; prothrombin time and partial thromboplastin time, and $\leq 1.5$ times the normal International Normalized Ratio (0.8-1.2), respectively; bilirubin level, $<2 \mathrm{mg} / \mathrm{dl}$ [ $30 \mathrm{~mol} / 1 ; 1.5$ times below the upper limit of the laboratory norm $(0-1.3 \mathrm{mg} / \mathrm{dl})]$; and aminotransferases level, $<2.5$ times of the upper limit of the laboratory norm (ALT, alanine aminotransferase $<45 \mathrm{U} / 1$, AST aspartate aminotransferase $<40 \mathrm{U} / \mathrm{l})$. The qualification process was based on a
Table I. Characteristics of the patient cohort.

\begin{tabular}{lc}
\hline Parameter & Patients, $\mathrm{n}^{\mathrm{a}}$ \\
\hline Sex & 27 \\
Female & 34 \\
Male & \\
Localization of primary focus & 46 \\
Digestive tract & 7 \\
Breast & 5 \\
Lung & 1 \\
Melanoma & 1 \\
Larynx & 1 \\
Endometrium & \\
Number of metastases (lesions in the liver) & 51 \\
1 & 8 \\
2 & 2 \\
3 & 10 \\
Other metastases outside the liver & 24 \\
Chemotherapy after brachytherapy & $2.7(1-7)$ \\
Number of applicators, mean (range)
\end{tabular}

${ }^{a}$ Unless otherwise indicated.

multi-disciplinary assessment of the patient by a surgeon, a radiologist, a clinical oncologist and a radiotherapist.

Course of application process. The application was performed under local anesthesia, subsequent to administering $0.5 \%$ Bupivacaine into the VIII-XI intercostal spaces and sedation with Midazolam (2-5 mg IV). The puncture of the metastatic lesion was performed with the patient in the supine position with an 18-gage biopsy needle (Chiba Biopsy Needle; Cook Medical LLC, Bloomington, ID, USA), followed by a rigid angiography steel guide wire (Ref. No. INT6F; Balton SP. o.o, Warsaw, Poland). Following this, an angiographic sheath with dilatator and a hemostatic valve was used (INT6F; Balton SP. o.o), according to the manufacturer's protocol. The radiotherapy was administered with the control of a multi-row computerized tomography (CT) scanner, equipped with the option for fluoroscopic examination (SOMATOM Sensation Open; Siemens Healthineers, Erlangen, Germany). A 16-gage angiographic sheath (Ref. no. INT6F; Balton SP. o.o) was introduced into the tumor area for interstitial brachytherapy. Catheters (size 1.84x350 mm; Varian Medical Systems, Inc., Palo Alto, CA, USA) were placed at 1-3 cm intervals, if possible according to the Paris System rules (12). Depending on the size of the tumor, an adequate number of catheters were inserted so that the entire volume of the tumor was covered during brachytherapy (Fig. 1). The positioning of the catheter was performed with CT scans with the simultaneous administration of a single-dose intravenous iodinated non-ionizing intravenous contrast agent (Ultravist 370, Iopromidum 768, $86 \mathrm{mg} / \mathrm{ml}$ ). Treatment planning was performed using the Brachyvision (version 10; Varian Medical Systems, Inc.) treatment planning system. An Iridium-192 source with a diameter 


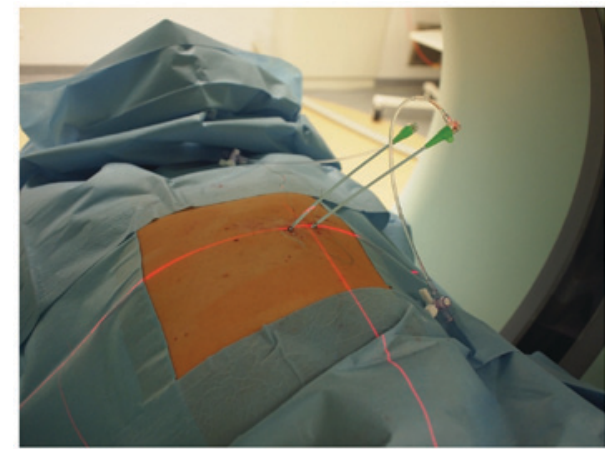

Figure 1. Application technique. Male, 61 years old, positioned on his back. The tumor was located in segment 4 of the liver, with 2 visible sheaths into tumor, without applicators.

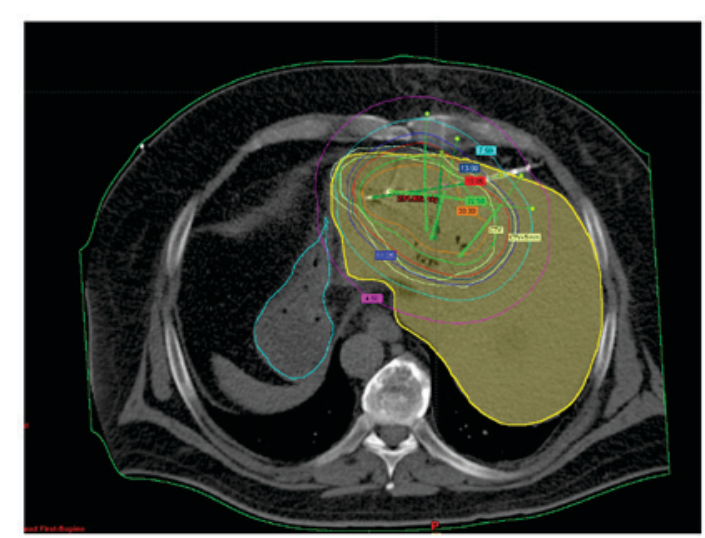

Figure 2. Treatment planning. Female, 55 years old, computed tomography scan of the liver. Visible tumor in segment 4 with applicators. Numbers in colored boxes indicate the isodose, The purple line indicates isodose 4,5 Gy, the light blue line indicates isodose 7,5 Gy, the dark blue line indicate isodose $13,5 \mathrm{~Gy}$, the red line indicates isodose $15 \mathrm{~Gy}$, the green line indicate isodose 22,5 and the orange line indicates isodose $30 \mathrm{~Gy}$. The inner light yellow line defines the CTV, and the outer light yellow line, defines CTV+5 mm. The yellow structure is the liver and the blue structure is the stomach.

of $0.6 \mathrm{~mm}$ and an average activity of $10 \mathrm{Ci}$ was used. The treatment was performed with a 24-channel GammaMedPlus ${ }^{\mathrm{TM}}$ iX (Varian Medical Systems, Inc.).

Treatment planning and dosimetry analysis. The clinical target volume included all metastatic changes visualized by CT examination with contrast on the day of application or images of metastasis resulting from fusion CT with contrast and magnetic resonance imaging (MRI) with contrast. The reference dose ranged from 15-25 Gy, depending on the ability of the patient to accept a treatment plan for tolerance of the organ at risk, determined based on published literature previous experience (13). The primary critical organ was the remaining healthy liver tissue. The limit was set to not exceed a 5 Gy dose in $2 / 3$ of healthy liver tissue ( $D_{2 / 3}<5$ Gy) (Fig. 2).

Follow-up treatment. In the post-treatment period, patients underwent periodic imaging studies including CT or MRI scans (4-6 times/year). To evaluate treatment response, RECIST 1.0 criteria were used. In certain patients, due to difficulties in interpretation of the CT image, MRI was also performed. Patients were also evaluated for early treatment toxicity using the Common Terminology Criteria for Adverse Events (CTCA) scale ver. 4.0 (14). Due to the short duration of the study, no late toxicity was assessed.

Statistical analysis. Dosimetry data are presented in mean \pm standard deviation and median (full range). Survival analysis was performed using a Kaplan-Meier survival analysis. Cox's proportional regression analysis and $\chi^{2}$ were used to analyze prognostic factors (dose in 90 and $100 \%$ isodoses, the effects of chemotherapy and the location of the primary tumor) with local relapse free survival (LRFS), progression free survival (PFS) and overall survival (OS) rates as endpoints. $\mathrm{P}<0.05$ was considered to indicate a statistically significant difference. Statistical analysis was performed in MedCalc Statistical Software version 17.9.7 (MedCalc Software bvba, Ostend, Belgium).

\section{Results}

Dosage and treatment planning. Within the group of 61 patients undergoing brachytherapy, 73 metastases were treated. Doses of $\geq 20$ Gy were administered to a group of 37 patients $(61 \%)$; a lower dose (15 Gy) was administered to the rest. The dose was selected based upon the tolerance of the critical organs. The fractional dose was within the range of the $90 \%\left(\mathrm{D}_{90}\right)$ and $100 \%\left(\mathrm{D}_{100}\right)$ isodoses. The mean $\mathrm{D}_{90}$ was $20.2 \pm 4.5 \mathrm{~Gy}$. The median $\mathrm{D}_{90}$ was $20 \mathrm{~Gy}$ (13-29 Gy). The mean $\mathrm{D}_{100}$ was $13.2 \pm 3.1 \mathrm{~Gy}$, and the median $\mathrm{D}_{100}$ was $13 \mathrm{~Gy}$ (7-20 Gy). The mean volume of the irradiated lesions was $59.1 \pm 49.7 \mathrm{~cm}^{3}$. The median volume of the irradiated lesions was $42.9 \mathrm{~cm}^{3}\left(2.7-174.9 \mathrm{~cm}^{3}\right)$. The mean volume that received $150 \%$ of the dose $\left(\mathrm{V}_{150 \%}\right)$ was $31.3 \pm 24.6 \mathrm{~cm}^{3}$. The median $\mathrm{V}_{150 \%}$ was $26.2 \mathrm{~cm}^{3}\left(1.8-94.5 \mathrm{~cm}^{3}\right)$. The mean volume that received $200 \%$ of the dose $\left(\mathrm{V}_{200 \%}\right)$ was $21.4 \pm 16.7 \mathrm{~cm}^{3}$. The median $\mathrm{V}_{200 \%}$ was $18.6 \mathrm{~cm}^{3}\left(1.5-64.1 \mathrm{~cm}^{3}\right)$.

The primary critical organ was the remaining healthy liver tissue. The dose in $2 / 3$ of normal liver volume $\left(D_{2 / 3}\right)$ was measured. The mean $\mathrm{D}_{2 / 3}$ was $1.9 \pm 1.2 \mathrm{~Gy}$, and the median $\mathrm{D}_{2 / 3}$ was 1.5 Gy (0.3-4.9 Gy).

Follow-up. In all patients, the mean follow-up time was 12.6 \pm 5.4 months, and the median follow-up time was 11 months (3-25 months). During the whole period of observation, progression of the treated cancer lesions was observed in 18 patients (29\%). It occurred in individual patients, on mean, after 10 (4-23) months of observation. The probability of 6-month LRFS was $88.7 \%$ in the whole group, and the 12-month LRFS was $70.7 \%$ (Fig. 3). During the follow-up period, disease progression was observed in 35 patients (57\%), and was defined as progression of the treated lesion, or the progression or appearance of other metastatic lesions. The probability of 6-month PFS was $78.1 \%$ and 12-month PFS was $53.8 \%$ (Fig. 4). During the follow-up period, 15 patients succumbed to the cancer $(24.6 \%)$. The rate of 6-month OS (6-month overall survival) was $96.7 \%$, and of 12-month OS was $79.6 \%$ (Fig. 5).

In the Cox regression analysis, $D_{100}$ was a statistically significant predictor of LRFS and PFS, but it was not significant in OS. $D_{90}$ was a statistically significant predictor of LRFS but it was not significant in PFS and OS. Lower doses $\left(\mathrm{D}_{90}\right.$ lower than 20 Gy and $D_{100}$ lower than 15 Gy) caused a deterioration 


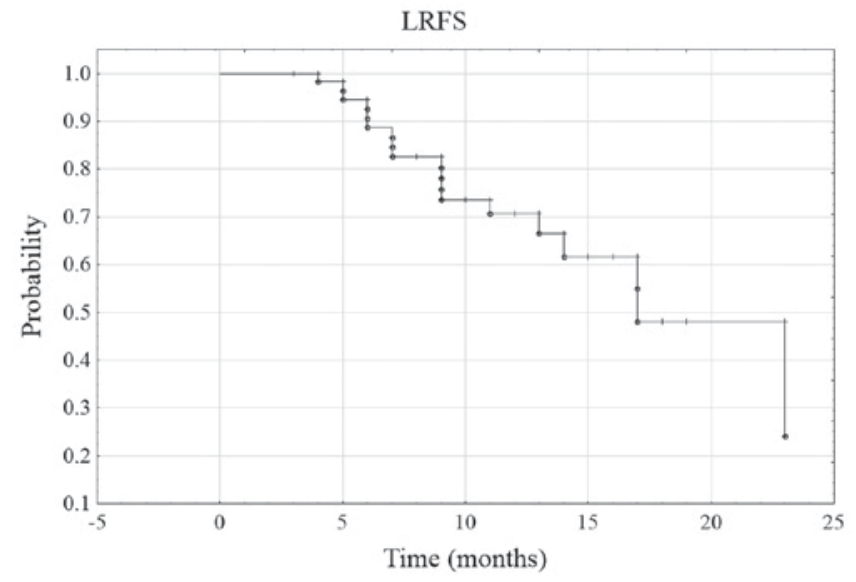

Figure 3. Kaplan-Meier curve of LRFS in whole group. LRFS, local recurrence-free survival.

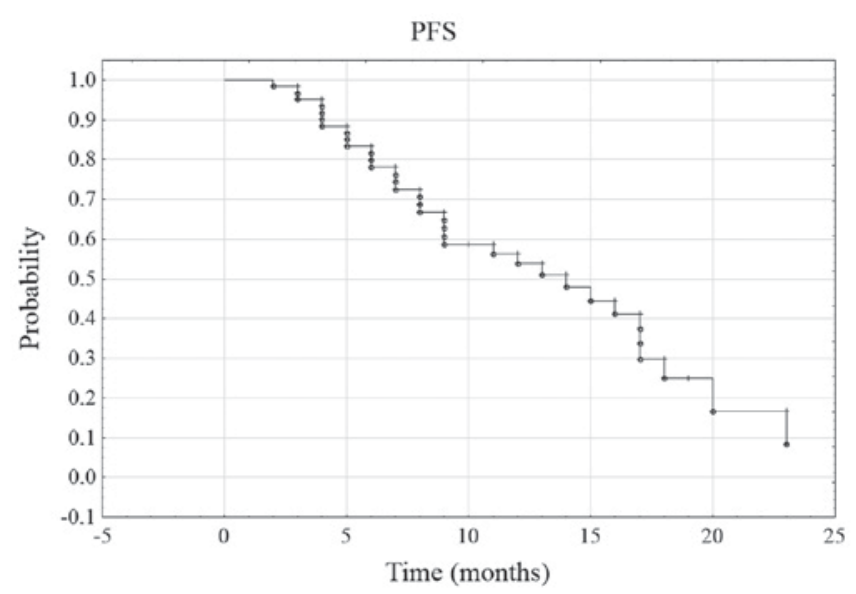

Figure 4. Kaplan-Meier curve of PFS in whole group. PFS, progression free survival.

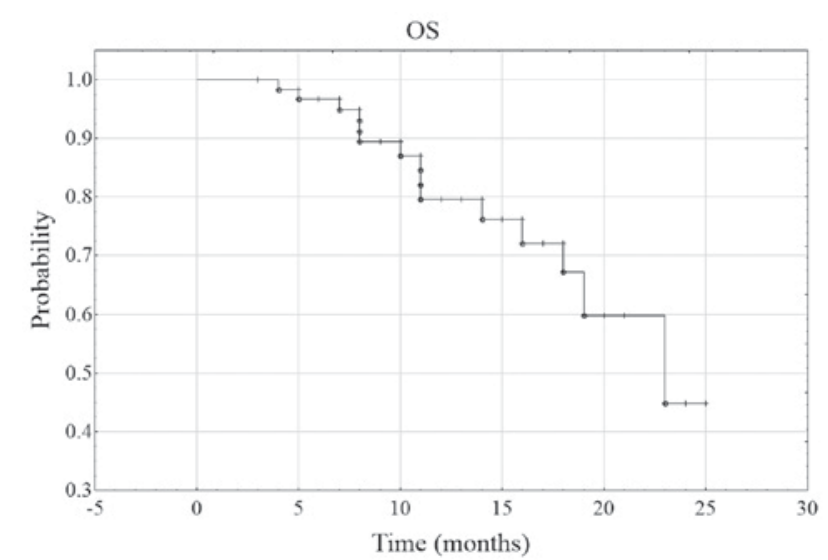

Figure 5. Kaplan-Meier curve of OS in whole group. OS, overall survival.

of LRFS. Chemotherapy and localization of cancer were not significant predictors of outcome (Table II).

Early toxicity of treatment. Complications following brachytherapy of liver metastases may result from the application of the treatment itself, and the effects of radiation on liver function (15). In all the patients, no serious complications (>grade 2 CTCA) were observed. Complications associated with the application process are presented in Table III. There were no adverse effects of radiation on liver function in the form of clinical symptoms or worsening of liver biochemical parameters, including levels of alanine transaminase, aspartate transaminase or bilirubin.

\section{Discussion}

Brachytherapy under CT control has been described as a safe and effective method for the treatment of primary and secondary liver lesions $(13,16-17)$. In the present study, brachytherapy under CT as a palliative method of treating liver metastases was demonstrated to be an effective and safe method for the patient and a technically feasible procedure. In an initial study, Ricke et al (13) achieved 6-month local control at a rate of $87 \%$ using 10-20 Gy doses. Subsequent studies also indicated good local control: In a phase II clinical study including patients with metastatic breast cancer (18), rates of local control were $97,93.5$ and $93.5 \%$ for 6,12 and 18 months, respectively. In these patients, the 6-, 12- and 18-month PFS rates were 53, 40 and $27 \%$, respectively, and the 6-, 12- and 18 -month OS rates were 97,79 and $60 \%$, respectively (18). Analysis of metastases in other primary sites also generated excellent results. Wieners et al (19), who studied metastatic cancer of the pancreas, identified local recurrence in only $10 \%$ of patients. Schippers et al (20), who analyzed neurogenic neoplasm metastases, only $11 \%$ of local recurrence was observed. Similarly, Bretschneider et al (21), who examined melanoma metastasis, obtained a local control rate of $90 \%$. In the present study, the 6- and 12-month LRFS rates were 90 and $64 \%$, respectively. These results were similar to the initial results in German centers, including the Radiology and Nuclear Medicine Clinic (Magdeburg) that have extensive experience in this type of treatment $(13,6-17,22)$. In the present study, the 6- and 12-month OS rate was high (97 and 80\%, respectively). It should be considered, however, that chemotherapy, which was applied following brachytherapy in $39 \%$ of patients, may have affected the OS rates.

Literature analysis indicated that good local control could be achieved at doses in the range of 15-25 Gy; however, in a number of previous studies there were no precise dosimetric data, and it is unclear which isodose was used (16-21). The majority of studies indicated that there was a marked dose dependence and no local recurrence after $\mathrm{D}_{100} 20.4$ Gy (22). Dose dependence in the range of 15-25 Gy was not identified in cases of hepatocellular carcinoma: Local control in these cases was high, at $94 \%$ (24). The analysis of the data from the Cox regression model of the present study indicated that local control of the tumor following brachytherapy depends on the dose in the $\mathrm{D}_{90}$ and $\mathrm{D}_{100}$ range. The treatment efficiency increases with increasing doses.

In the analyzed group, the majority of patients were those with the primary cancer lesion located in the gastrointestinal tract; only 15 patients had other primary tumors. There were no statistically significant differences in prognosis between these groups, but this may be due to the small number of patients in the groups. The data from previous studies indicate a similar prognosis for primary cancer of the pancreas, 
Table II. Cox regression analysis.

\begin{tabular}{|c|c|c|c|c|}
\hline Characteristics & $\chi^{2}$ & HR & $95 \%$ CI & P-value \\
\hline \multicolumn{5}{|l|}{$\mathrm{D}_{100}$} \\
\hline LRFS & 8.38 & 0.77 & $0.63-0.94$ & 0.01 \\
\hline PFS & 6.55 & 0.85 & $0.75-0.97$ & 0.02 \\
\hline OS & 3.80 & 0.82 & $0.66-1.02$ & 0.07 \\
\hline \multicolumn{5}{|l|}{$\mathrm{D}_{90}$} \\
\hline LRFS & 6.24 & 0.85 & $0.73-0.98$ & 0.03 \\
\hline PFS & 1.97 & 0.94 & $0.85-1.03$ & 0.17 \\
\hline OS & 1.45 & 0.92 & $0.78-1.06$ & 0.25 \\
\hline \multicolumn{5}{|l|}{ CHT } \\
\hline LRFS & 3.08 & 2.26 & $0.89-5.76$ & 0.09 \\
\hline PFS & 2.33 & 1.68 & $0.86-3.27$ & 0.13 \\
\hline OS & 0.01 & 0.16 & $0.38-2.95$ & 0.91 \\
\hline \multicolumn{5}{|c|}{ Localisation (colon cancer vs. other neoplasms) } \\
\hline LRFS & 1.59 & 2.09 & $0.60-7.25$ & 0.24 \\
\hline PFS & 2.31 & 1.60 & $0.80-4.30$ & 0.15 \\
\hline $\mathrm{OS}$ & 0.04 & 1.12 & $0.35-3.57$ & 0.84 \\
\hline
\end{tabular}

LRFS, local recurrence-free survival; PFS, progression-free survival; OS, overall survival; $\mathrm{D}_{100}, 100 \%$ isodose; $\mathrm{D}_{90}, 90 \%$ isodose; CHT, chemotherapy; CI, confidence interval; HR, hazard ratio.

Table III. Early toxicity of treatment.

\begin{tabular}{lccc}
\hline Types of toxicity & CTCAE Grade 1, n (\%) & CTCAE Grade 2, n (\%) & CTCAE Grade 3-5, n (\%) \\
\hline Pain & $14(23)$ & $4(7)$ & 0 \\
Nausea or vomiting & $30(49)$ & 0 & 0 \\
Subscapular Bleeding & $2(3)$ & 0 & 0 \\
Pneumothorax & $1(2)$ & 0 & 0 \\
\hline
\end{tabular}

CTCAE, common terminology criteria for adverse events v.4.0.

stomach or kidney, or in melanoma or neuroendocrine tumors (19-21,24,25). However, these results should be treated with caution as they are based on retrospective data, and not on a large number of patients.

The data from the literature also indicated a good tolerance and low toxicity of treatment. Ricke and Wust (22) described pain and nausea in patients, mostly at grade 1 and 2 on the CTCA scale, with $<1 \%$ at grade 3 . The authors identified pneumothorax in $10 \%$ of cases, CTCA grade 2 hemorrhage in $3 \%$ of cases, gastric and duodenal ulcers in $1 \%$ of cases and liver abscesses in $1 \%$ of cases. In the phase II study conducted by Wieners et al (18), only $1.5 \%$ of patients exhibited severe hemorrhagic complications. Similarly, in the Indian study, no significant complications were identified.

Similar results were identified in the patient cohort. The toxicity of treatment was low, with the majority at grade 1 . None of the patients exceeded the dose of 5 Gy in 2/3 healthy liver tissue, and the dose in $1 \mathrm{~cm}^{3}$ of the stomach or duodenum was $<15 \mathrm{~Gy}$, which is consistent with data from the literature (21-22,26). No biochemical evidence of liver toxicity was identified in the analyzed group, in the form of elevated liver enzymes, which is consistent with previous analysis (15). Lack of toxicity in grade 3 indicates good tolerance of treatment, similar to stereotactic radiotherapy (27).

One limitation of the treatment technique is the size and location of the lesion. The patients with lesions $<8 \mathrm{~cm}$ were eligible for treatment, similar to the criterion used by Ricke et al (13). Owing to the potential risk of bleeding, patients whose metastatic lesions were located in the proximity of large vessels were not eligible. On the basis of the analyzed group of patients, it could be concluded that the liver brachytherapy technique is relatively easy to administer, taking into account compliance with the qualification criteria. Another limitation of this study was the analysis of singular groups in which the number of patients was small.

Brachytherapy of liver metastases is an effective method for local metastatic treatment. The effectiveness of the treatment is probably dose-dependent, and increases with increasing dosage. This treatment is well-tolerated and the toxicity of brachytherapy is negligible. 


\section{Competing interests}

The authors declare that there are no competing interests.

\section{References}

1. Turdean S, Gurzu S, Turcu M, Voidăzan S and Sin A: Liver metastases: Incidence and clinicopathological data. Acta Medica Marisiensis 58: 254-258, 2012.

2. Tarasik A, Jaroszewicz J and Januszkiewicz M: Surgical treatment of liver tumors - own experience and literature review. Clin Exp Hepatol 3: 1-8, 2017.

3. Swaid F, Downs D and Rosemurgy AS: A practical approach to liver metastasis from unknown primary cancer: What surgeons need to know. Cancer Genet 209: 559-566, 2016

4. Hijazi H, Campeau MP, Roberge D, Donath D, Lapointe R, Vanderbroucke-Menu F, Taussky D, Boudam K, Chan G, Bujold A and Delouya G: Stereotactic body radiotherapy for inoperable liver tumors: Results of a single institutional experience. Cureus 8: e935, 2016.

5. de Baere T, Tselikas L, Yevich S, Boige V, Deschamps F, Ducreux M, Goere MD, Nguyen F and Malka D: The role of image-guided therapy in the management of colorectal cancer metastatic disease. Eur J Cancer 75: 231-242, 2017.

6. Kennedy AS: Radiation oncology approaches in liver malignancies. Am Soc Clin Oncol Educ Book: e150-e155, 2014.

7. Dawood O, Mahadevan A and Goodman KA: Stereotactic body radiation therapy for liver metastases. Eur J Cancer 45: 2947-2959, 2009.

8. Brethsneider T, Ricke J, Gebauer B and Streitparth F: Image-guided high dose rate brachytherapy of malignances in various organs-technique, indications and perspectives. J Contemp Brachytherapy 8: 251-261, 2016.

9. Kordzińska-Cisek I, Brzozowska A, Cisek P, Kijek J and Mazurkiewicz M: The role of radiotherapy in the treatment of hepatic neoplasms. Oncol Radiother 36: 53-60, 2016.

10. Eisenhauer EA, Therasse P, Bogaerts J, Schwartz LH, Sargent D, Ford R, Dancey J, Arbuck S, Gwyther S, Mooney M, et al: New response evaluation criteria in solid tumours: Revised RECIST guideline (version 1.1). Eur J Cancer 45 228-247, 2009

11. Picot J, Cooper K, Bryant J and Clegg AJ: The clinical effectiveness and cost-effectiveness of Bortezomib and thalidomide in combination regimens with an alkylating agent and a corticosteroid for the first-line treatment of multiple myeloma: A systematic review and economic evaluation. Health Technol Assess 15: 1-204, 2011.

12. Marinello G and Pierquin B: The Paris system, optimization of dose, and calculation of treatment time. In: A practical manual of Brachytherapy. Medical Physics Publishing, Madison, WI, pp53-68, 1997.

13. Ricke J, Wust P, Wieners G, Beck A, Cho C, Seidensicker M, Pech M, Werk M, Rosner C, Hänninen EL, et al: Liver malignancies: CT-guided interstitial brachytherapy in patients with unfavorable lesions for thermal ablation. J Vasc Interv Radiol 15: 1279-1286, 2004.

14. U.S. Department Of Health And Human Services, National Institutes of Health, National Cancer Institute: Common Terminology Criteria for Adverse Events (CTCAE) Version v4.03. http://www.oncology.tv/Symptom Management/ NationalCancerInstituteUpdatesCTCAEtov403.aspx. Accessed June 14,2010
15. Cisek P, Kordzińska-Cisek I, Charkot $Ł$, Korona $P$, Kieszko D, Bilski M, Brzozowska A, Janiszewski $M$ and Grzybowska-Szatkowska L: Biochemical liver function markers after CT-guided brachytherapy for liver metastases. Oncol Radiotherap 39: 67-75, 2017.

16. Ricke J, Mohnike K, Pech M, Seidensticker M, Rühl R, Wieners G, Gaffke G, Kropf S, Felix R and Wust P: Local response and impact on survival after local ablation of liver metastases from colorectal carcinoma by computed tomography-guided high-dose-rate brachytherapy. Int J Radiat Oncol Biol Phys 78: 479-485, 2010.

17. Mohnike K, Wieners G, Pech M, Seidensticker M, Rühl R, Lopez-Haenninen E and Ricke J: Image-guided interstitial high-dose-rate brachytherapy in hepatocellular carcinoma. Dig Dis 27: $170-174,2009$

18. Wieners G, Mohnike K, Peters N, Bischoff J, Kleine-Tebbe A, Seidensticker R, Seidensticker M, Gademann G, Wust P, Pech M and Ricke J: Treatment of hepatic metastases of breast cancer with CT-guided interstitial brachytherapy-a phase II-study. Radiother Oncol 100: 314-319, 2011.

19. Wieners G, Schippers AC, Collettini F, Schnapauff D, Hamm B and Gebauer B: CT-guided high-dose-rate brachytherapy in the interdisciplinary treatment of patients with liver metastases of pancreatic cancer. Hepatobiliary Pancreat Dis Int 14: 530-538, 2015.

20. Schippers AC, Collettini F, Steffen IG, Wieners G, Denecke T, Pavel M, Wust P and Gebauer B: Initial experience with CT-guided high-dose-rate brachytherapy in the multimodality treatment of neuroendocrine tumor liver metastases. J Vasc Interv Radiol 28: 672-682, 2017.

21. Bretschneider T, Mohnike K, Hass P, Seidensticker R, Göppner D, Dudeck O, Streipath F and Ricke J: Efficacy and safety of image-guided interstitial single fraction high-dose-rate brachytherapy in the management of metastatic malignant melanoma. J Contemp Brachytherapy 7: 154-160, 2015.

22. Ricke J and Wust P: Computed tomography-guided brachytherapy for liver cancer. Semin Radiat Oncol 24: 287-293, 2011.

23. Mohnike K, Wieners G, Schwartz F, Seidensticker M, Pech M, Ruehl R, Wust P, Lopez-Hänninen E, Gademann G, Peters N, et al: Computed tomography-guided high-dose-rate brachytherapy in hepatocellular carcinoma: Safety, efficacy, and effect on survival. Int J Radiat Oncol Biol Phys 78: 172-179, 2010.

24. Geisel D, Denecke T, Collettini F, Grieser C, Wust P, Thuss-Patence P, Hamm B and Gebaueret B: Treatment of hepatic metastases from gastric or gastroesophageal adenocarcinoma with computed tomography-guided high-dose-rate brachytherapy (CT-HDRBT). Anticancer Res 32: 5453-5458, 2012.

25. Geisel D, Collettini F, Denecke T, Grieser C, Flörcken A, Wust P, Hamm B and Gebaueret B: Treatment for liver metastasis from renal cell carcinoma with computed-tomography-guided high-dose-rate brachytherapy (CT-HDRBT): A case series. World J Urol 31: 1525-1530, 2013.

26. Sharma DN, Thulkar S, Sharma S, Gandhi AK, Haresh KP, Gupta S, Rath GK and Julka PK: High-dose-rate interstitial brachytherapy for liver metastases: First study from India. J Contemp Brachytherapy 5: 70-75, 2013.

27. Joo JH, Park JH, Kim JC, Yu CS, Lim SB, Park IJ, Kim TW, Hong YS, Kim KP and Yoon SM: Local control outcomes using stereotactic body radiation therapy for liver metastases from colorectal cancer. Int J Radiat Oncol Biol Phys 99: 876-883, 2017. 